\title{
Sigmoid motility in diverticular disease and the irritable bowel syndrome
}

\author{
I F TROTMAN AND J J MISIEWICZ \\ From the Department of Gastroenterology and Nutrition, Central Middlesex Hospital, London
}

SUMMARY Intraluminal pressures were measured with four open ended, water perfused tubes in the fasting state and after a standard liquid meal $(400 \mathrm{KCal}, 375 \mathrm{ml}$, protein $15 \mathrm{~g}$, carbohydrate $55 \mathrm{~g}$, lipid $13.4 \mathrm{~g}$ ) in six patients with sigmoid diverticular disease, 20 with the irritable bowel syndrome and in 13 controls. The pressure sensors were positioned in the true sigmoid colon at colonoscopy at $25,35,45$, and $55 \mathrm{~cm}$ from the anus. Colonic pressures were significantly higher in diverticular disease than in controls before $(p<0.02)$ and after the meal $(p<0.002)$, some pressure amplitudes exceeding $300 \mathrm{~cm} \mathrm{H}_{2} \mathrm{O}$. Patients with the irritable bowel syndrome had lower $(\mathrm{p}<0.05)$ pressures than controls before the meal. Postprandial sigmoid pressures were within the mean \pm 2 SD of controls in 10 , above in two and below in eight patients with the irritable bowel. Hypercontractility of the sigmoid colon in the irritable bowel syndrome was not confirmed under the conditions of this study. The association between sigmoid diverticulosis and high intraluminal pressures is confirmed.

Measurements of motility of the alimentary tract are important in the understanding of gut physiology and the mechanism of symptoms. While the oesophagus, stomach and small intestine are readily accessible by oral transtubation, this does not apply to the colon. Most of the published data on colonic intraluminal pressures (IP's) derive from tube assemblies, positioned in the bowel through a rigid sigmoidoscope. Consequently the more proximal parts of the large intestine, including the potentially very interesting sigmoid, have remained unexplored. In this study we report a method for placing pressure sensitive tube assemblies in the more proximal colon at colonoscopy. Results of intraluminal pressure measurements in the sigmoid colon in controls, patients with the irritable bowel syndrome (IBS), or with diverticular disease (DD) are described.

\section{Methods}

PATIENTS

Patients were admitted to hospital for colonoscopy having stopped all medication and eaten a low

Address for correspondence: Dr Ivan Trotman, Dept of Gastroenterology, Central Middlesex Hospital, Acton Lane, London NW10 7NS

Received for publication 22 July 1987. residue diet for $48 \mathrm{~h}$ previously. Bowel cleansing was done with 11 oral mannitol $10 \%$ on the morning of colonoscopy, under sedation with pethidine $50 \mathrm{mg}$ and diazepam $10-20 \mathrm{mg}$ iv. After routine examination of the bowel to the caecum the colonoscope was withdrawn to the transverse colon and any loops present were straightened. Four angiology guide wires (Kimal Scientific 5SU400, length $4 \mathrm{~m}$ ) were introduced into the bowel lumen through the biopsy channel; the colonoscope was then withdrawn, leaving the guide wires in situ. Radio-opaque open ended PVC tubes (OET's, length $1.7 \mathrm{~m}$, id $1.2 \mathrm{~mm}$ ) marked at intervals of $10 \mathrm{~cm}$ were threaded over each guide wire for approximately $1 \mathrm{~m}$ of their length. The guide wires were then withdrawn and the four OET's taped securely to the buttock.

After a normal supper and the night spent in the ward, the patients returned to the laboratory, having fasted since midnight. The position of the OET's was adjusted under fluoroscopic control and with reference to the external markings, so, that the tips were at $25,35,45$, and $55 \mathrm{~cm}$ from the anal margin (Fig. 1). The OET's were connected to external pressure transducers (Type 4-327-1221, Consolidated Electrodynamics); OET's and transducers were perfused with distilled water $0.2 \mathrm{ml} / \mathrm{min}$ by a pneumohydraulic pump (Mui Scientific). The IP's were recorded on a 


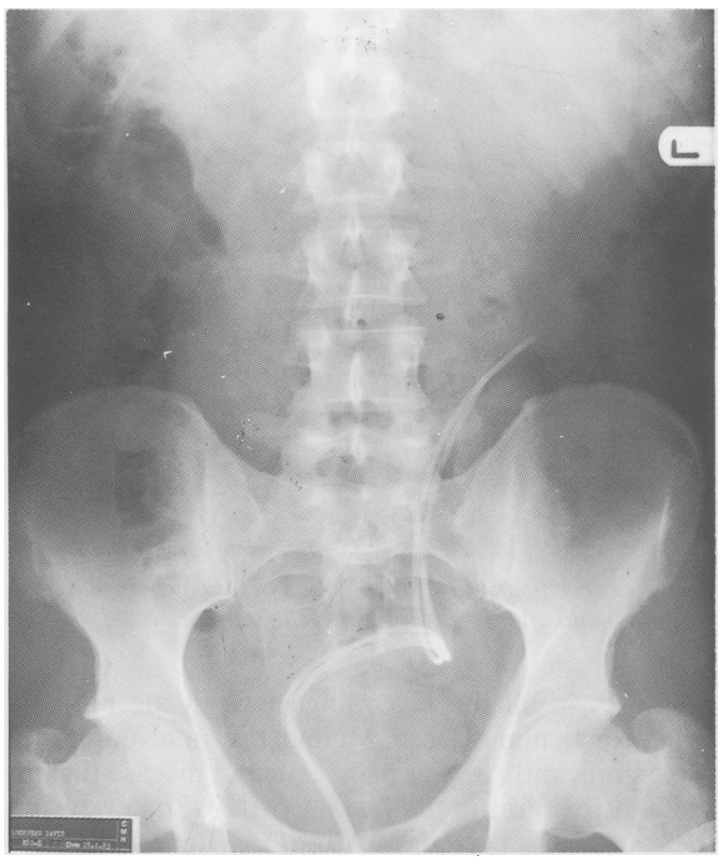

Fig. 1 Abdominal radiograph to showing tube assembly in situ.

multichannel Devices penwriter at paper speed of 25

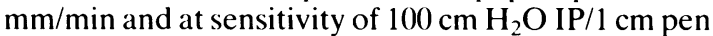
deflection. The position of the OET's was rechecked fluorescopically at the completion of the study: the tube assembly was in the same location at the end of the measurements in all the studies.

All pressure records were made with the patients seated comfortably on a couch in a semi recumbent position. After a 30 minute pause, basal fasting colonic IP's were measured for 30 minutes. Intraluminal pressure records were continued during, and for 30 minutes after a standard liquid meal (Clinifeed $400,375 \mathrm{ml}$ containing protein $15 \mathrm{~g}$, carbohydrate $55 \mathrm{~g}$, lipid $13.4 \mathrm{~g}, 400 \mathrm{KCal})$.

The intraluminal pressure records for the fasting and the postmeal periods were analysed with respect to percent duration of activity (\%DA), median maximal amplitude (MMA), and the motility index (MI). Pressures of less than $10 \mathrm{~cm} \mathrm{H}_{2} \mathrm{O}$ amplitude were ignored for the purpose of analysis. Percent duration of activity was defined as the sum of durations of all pressure events expressed as the percentage of the time of each observation period. Median maximal amplitude was determined by dividing each 30 minute period into one minute epochs, measuring the highest intraluminal pressure amplitude in each epoch and calculating the median for the 30 minute observation period. Motility index was derived as percent duration of activity $\times$ median maximal amplitude. For the purposes of analysis the results from the four simultaneously recording OET's were combined and thus pertain to a colonic study segment lying between 25 and $55 \mathrm{~cm}$ from the anus. Statistical analysis was done using the Mann Whitney $\mathrm{U}$ test, comparing motility index in each patient group in each observation period.

Thirty nine patients were studied (Table 1). All six with diverticular disease had sigmoid involvement shown on barium enema and recent symptoms related to diverticular disease, but all were symptomless at the time of the study.

In the 20 patients with irritable bowel syndrome the diagnosis was established on the usual criteria of abdominal pain and disturbed bowel habit in the presence of normal investigations. All the patients with IBS had a normal sigmoidoscopy, barium enema, blood count and ESR and a stool culture if diarrhoea was a symptom. Additional investigations in this group included barium meal (seven), endoscopy (11), oral cholecystogram (six), IVU (two), abdominal CT scan (two), and Lundh test meal and small intestinal mucosal biopsy (two), colonoscopy (four): all of these tests were normal. Ten patients had been seen by a psychiatrist and seven had previous abdominal surgery for their symptoms: hysterectomy (four), cholecystectomy (two), laparotomy for pain (three), Two patients had more than one operation, but none had operations involving the gut. The predominant symptom in all the patients with irritable bowel syndrome was abdominal pain, perceived in the left (13), or right (four) iliac fossa, or poorly localised (three). Eight patients were constipated, four had diarrhoea, seven alternating diarrhoea and constipation and one a normal bowel habit. All the patients with irritable bowel syndrome were symptomatic at the time of the study.

The 13 control patients underwent colonoscopy because of rectal bleeding (five), for polyp check

\section{Table 1 Details of patients studied}

\begin{tabular}{lc} 
Controls & \\
$n$ & 13 \\
Male/female & $7: 6$ \\
Median age & 64 \\
Range & $29-80$ \\
Irritable bowel & \\
$n$ & 20 \\
Male/female & $9: 11$ \\
Median age & 40 \\
Range & $22-73$ \\
Diverticular disease & \\
n & 6 \\
Male/female & $4: 2$ \\
Median age & 68 \\
Range & $59-75$ \\
\hline
\end{tabular}


(five), anaemia (two), and weight loss (one). None of these patients had abdominal pain and all were symptom free and with a normal bowel habit at the time of study.

Each patient gave informed consent to the study, which was approved by the local ethical committee.

\section{Results}

All the patients tolerated the study well and there were no unwanted effects associated with the procedure. Colonoscopy was complete to the caecum in all the subjects and macroscopically normal in controls and the patients with irritable bowel syndrome; colonic diverticular were the only abnormal finding in the diverticular disease group. Values of the three variables of motility in individuals before and after the standard meal are shown in Table 2 and in Figs 2, 3 , and 4 .

\section{EFFECT OF THE MEAL}

The $400 \mathrm{KCal}$ meal effectively stimulated colonic intraluminal pressure in all three groups of patients (Table 2, Fig. 4). Mean percentage increase in motility index after the meal was $111 \%$ above basal in controls and in the patients with diverticular disease. The corresponding increase in the irritable bowel syndrome group was $198 \%$.

DIVERTICULAR DISEASE

In patients with diverticular disease colonic pressure activity as assessed by motility index was significantly higher than in the controls in the basal $(p<0.02)$ and in the post-prandial $(p<0.002)$ periods. These differences were mainly the result of high intraluminal

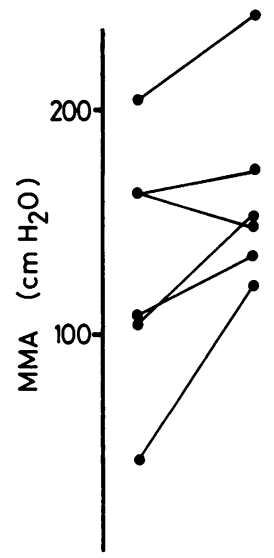

DD

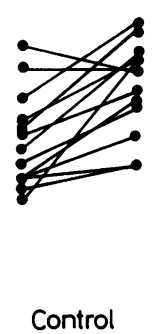

Fig. 2 Mean maximal amplitudes (MMA) in $\mathrm{cm} \mathrm{H}_{2} \mathrm{O}$ before (left columns) and after (right columns) the standard meal.

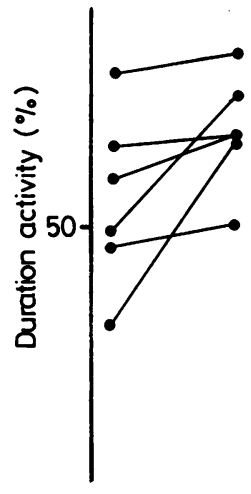

DD

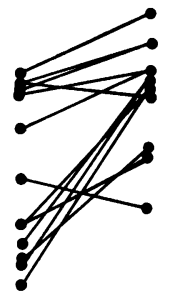

Controls

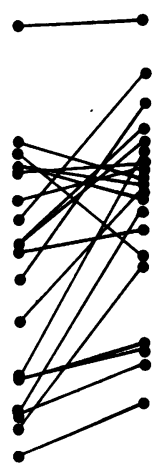

IBS
Fig. 3 Percentage duration of activity $(\% D A)$ before (left columns) and after (right columns) the standard meal.

pressures in all the recording leads in the patients with diverticular disease. Median maximal amplitude was significantly higher in diverticular disease than in the controls during the fasting $(p<0.05)$ and during the postmeal periods $(\mathrm{p}<0 \cdot 01)$. High amplitude pressure peaks, occasionally exceeding $300 \mathrm{~cm} \mathrm{H}_{2} \mathrm{O}$ were often recorded in diverticular disease.
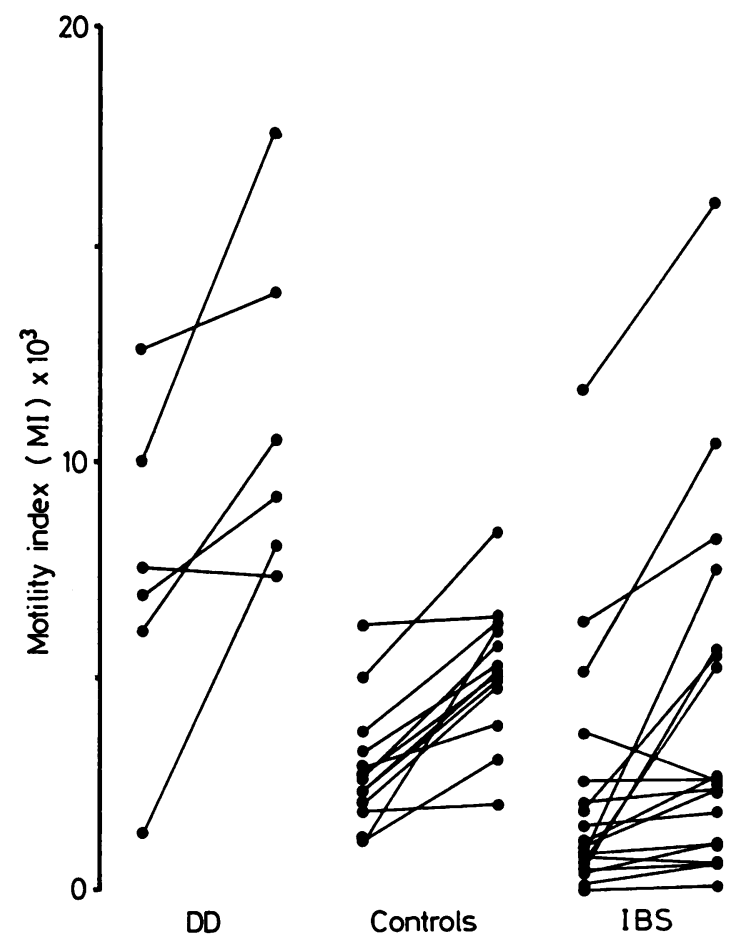

IBS
Fig. 4 Motility index (MI) before (left columns) and after (right columns) the standard meal. 
Table 2 Individual values of motility variables. $\% D A=$ percentage duration of activity; $M M A=$ mean maximal amplitude; $M I=$ motility index

\begin{tabular}{|c|c|c|c|c|c|}
\hline \multicolumn{3}{|l|}{ Basal } & \multicolumn{3}{|c|}{ Postprandial } \\
\hline$\% D A$ & $M M A$ & $M I$ & $\% D A$ & $M M A$ & $M I$ \\
\hline \multicolumn{6}{|c|}{ Controls } \\
\hline 60 & 85 & 5100 & 70 & 120 & 8400 \\
\hline 30 & 40 & 1200 & 58 & 105 & 6090 \\
\hline 58 & 50 & 1200 & 56 & 70 & 3920 \\
\hline 50 & 75 & 3750 & 60 & 105 & 6300 \\
\hline 56 & 50 & 2800 & 60 & 86 & 5160 \\
\hline 33 & 71 & 2343 & 56 & 90 & 5040 \\
\hline 57 & 110 & 6270 & 65 & 100 & 6500 \\
\hline 32 & 63 & 2016 & 45 & 108 & 4860 \\
\hline 27 & 100 & 2700 & 58 & 100 & 5800 \\
\hline 58 & 56 & 3248 & 65 & 83 & 5395 \\
\hline 23 & 50 & 1150 & 56 & 56 & 3136 \\
\hline 41 & 45 & 1845 & 36 & 56 & 2016 \\
\hline 28 & 73 & 2044 & 46 & 118 & 5428 \\
\hline \multicolumn{6}{|c|}{ Irritable bowel syndrome } \\
\hline 20 & 40 & 800 & 26 & 30 & 780 \\
\hline 45 & 20 & 900 & 63 & 120 & 7560 \\
\hline 49 & 40 & 1960 & 74 & 75 & 5550 \\
\hline 31 & 60 & 1860 & 55 & 50 & 2750 \\
\hline 52 & 18 & 936 & 58 & 20 & 1160 \\
\hline 45 & 115 & 5175 & 65 & 160 & 10400 \\
\hline 43 & 35 & 1505 & 47 & 40 & 1880 \\
\hline 58 & 20 & 1160 & 53 & 50 & 2650 \\
\hline 12 & 38 & 456 & 40 & 29 & 1160 \\
\hline 14 & 11 & 154 & 23 & 29 & 667 \\
\hline 20 & 25 & 500 & 27 & 23 & 621 \\
\hline 57 & 45 & 2565 & 59 & 44 & 2596 \\
\hline 21 & 35 & 735 & 60 & 88 & 5280 \\
\hline 15 & 37 & 555 & 51 & 110 & 5610 \\
\hline 7 & 10 & 70 & 16 & 10 & 160 \\
\hline 38 & 29 & 1102 & 69 & 35 & 2415 \\
\hline 62 & 34 & 2108 & 56 & 44 & 2464 \\
\hline 60 & 63 & 3780 & 42 & 63 & 2646 \\
\hline 83 & 140 & 11620 & 84 & 190 & 15960 \\
\hline 58 & 109 & 6322 & 54 & 154 & 8316 \\
\hline \multicolumn{6}{|c|}{ Diverticular disease } \\
\hline 64 & 109 & 6976 & 68 & 135 & 9180 \\
\hline 32 & 43 & 1376 & 66 & 122 & 8052 \\
\hline 58 & 106 & 6148 & 68 & 154 & 10472 \\
\hline 46 & 165 & 7590 & 50 & 149 & 7450 \\
\hline 49 & 206 & 10094 & 72 & 243 & 17496 \\
\hline 77 & 164 & 12628 & 80 & 174 & 13920 \\
\hline
\end{tabular}

IRRITABLE BOWEL SYNDROME

Variables of motility recorded in the irritable bowel syndrome patients were widely scattered (Table 2). The basal motility index was significantly $(\mathrm{p}<0.05)$ lower in irritable bowel syndrome patients than in the controls, but there were no significant differences from the control group after the meal.

The postprandial motility index in 10 of the 20 irritable bowel syndrome patients was within the mean and two standard deviations of the motility index in the controls. It was above this normal range in only two, and below in eight. Comparison with diverticular disease showed the motility index in irritable bowel syndrome was significantly lower before $(p<0 \cdot 02)$ and after the meal $(p<0 \cdot 002)$. The relatively low intraluminal pressure activity in irritable bowel syndrome was present in all the recording leads.

Correlation between the various symptoms of irritable bowel syndrome and the motility index were not apparent. Two patients experienced their typical pain during the study; colonic intraluminal pressure decreased in both.

\section{Discussion}

Methodologically this study differs from most other published data pertaining to the measurement of colonic intraluminal pressure in two important respects.

First, the pressure sensitive OET's were positioned within the colonic lumen using a colonoscope, rather than a rigid sigmoidoscope. The distance from the anus of the most proximal pressure sensors in many recent studies is stated to be $20 \mathrm{~cm}$, or less. ${ }^{1-9}$ Given that the bowel usually stretches ahead of the rigid sigmoidoscope and that there is likely to be some retraction after the instrument is withdrawn, these distances probably err on the optimistic. ${ }^{10}$ Although the data and the conclusions drawn from them in these various studies are not disputed, it could be argued that many of them pertain to the rectum rather than to the sigmoid colon proper; it remains to be shown whether the manometric properties of the two regions are similar. In the present study the OET's were realiably sited in the true sigmoid.

Second, the pressure records were analysed by combining the results from all four recording sites, spanning the sigmoid colon over a $30 \mathrm{~cm}$ study segment. The intraluminal pressure records from the four recording sites were qualitatively similar, although segmental pressure activity at one recording site could coincide with a period of motor quiescence at an adjacent site, only $10 \mathrm{~cm}$ distant; this has been commented on many times before. By combining the intraluminal pressure records and expressing the results in terms of a study segment the problem of the great variability of colonic motor activity is to some extent overcome. The assumption made in this technique is that the sigmoid study segment investigated in the present experiment is functionally homogenous. This contention is supported by the lack of any obvious quantitative differences in the intraluminal pressure records obtained from the four recording sites.

Intraluminal pressure records are dependent, to some extent, on the nature of the pressure sensors used to detect them. Thus water-filled microballoons are extremely sensitive to even the slightest deforma- 
tion, air filled balloons are less sensitive and OET's least sensitive of the three. Open ended PVC tubes used in this study were certainly capable of recording very high pressures in the patients with diverticular disease, so serious under-recording problems are unlikely.

The three clinical groups were not ideally matched for age and sex. Although this could have affected the results, this seems unlikely.

Bowel cleansing was necessary before the procedure. It is possible that an empty colon may have affected the pressure record. Pressures were measured $18 \mathrm{~h}$ after the colonoscopy, however, and the OET's were faecally soiled on withdrawal at the end of the test. Intergroup comparisons should be valid, as all patients followed an identical protocol and colonic cleansing was complete in all the three clinical groups studied: faeces were absent in all the subjects on colonoscopic inspection of the bowel to the caecum.

After the original observations of Arwidsson and Koock, ${ }^{11}$ this is the only other study which shows that intraluminal pressures in the sigmoid colon of patients suffering from colonic diverticular are significantly higher than in controls. It is noteworthy that Arwidsson et al, used a $30 \mathrm{~cm}$ rigid sigmoidoscope; the discrepant results of some other studies ${ }^{1}$ are probably the result of pressure sensors being located below the sigmoid colon, which was the site of the diverticular and therefore the likely location of the abnormal colonic muscle.

In the light of the preceding discussion, the observations made in the patients with the irritable bowel syndrome in the present study are interesting, because they suggest that, contrary to the generally accepted notion, the sigmoid colon is hypomotile, rather than hypersegmenting in this condition. It has been reported that patients with irritable bowel syndrome exhibit some features of autonomic arousal, ${ }^{8}$ so that sigmoid hypomotility in irritable bowel syndrome could be caused by increased sympathetic tone - inhibitory sympathetic influence on colonic smooth muscle has been shown to be present in vivo. ${ }^{912}$ Thus pain in irritable bowel syndrome may be the result of overdistention of a generally inhibited bowel and it may be relevant that the colon in irritable bowel syndrome is hypersensi- tive to distending stimuli. ${ }^{1314}$ If this observation is confirmed, it may suggest new approaches to the treatment of irritable bowel syndrome.

\section{References}

1 Weinreich J, Andersen D. Intraluminal pressure in the sigmoid colon. II. Patients with sigmoid diverticula and related conditions. Scand J Gastroenterol 1976; 11: 581-6.

2 Holdstock DJ, Misiewicz JJ, Waller SL. Observations on the mechanism of abdominal pain. Gut 1969; 10: 19-31.

3 Snape WJ Jr, Carlson GM, Cohen S. Colonic myoelectric activity in the irritable bowel syndrome. Gastroenterology 1976; 70: 326-30.

4 Snape WJ Jr, Carlson GM, Matarazzo GA, Cohen S. Evidence that abnormal myoelectrical activity produces colonic motor dysfunction in the irritable bowel syndrome. Gastroenterology 1977; 72: 383-7.

5 Snape WJ Jr, Wright SH, Battle WM, Cohen S. The gastrocolic response: evidence for a neural mechanism. Gastroenterology 1979; 77: 1235-40.

6 Sun EA, Snape WJ Jr, Cohen S, Renny A. The role of opiate receptors and cholinergic neurons in the gastrocolic response. Gastroenterology 1982; 82: 689-93.

7 Taylor I, Darby C, Hammond P, Basu P. Is there a myoelectrical abnormality in the irritable colon syndrome? Gut 1978; 19: 391-5.

8 Palmer R, Stonehill E, Crisp AH, Misiewicz JJ, Waller SL. Psychological characteristics of patients with irritable bowel syndrome. Postgrad Med J 1974; 50: 416-9.

9 Abrahamsson H, Dotevall G. Effects of propranolol on colonic pressure in patients with irritable bowel syndrome. Scand J Gastroenterol 1981; 16: 1021-4.

10 Nivatvongs S, Fryd DS. How far does the proctosigmoidoscope reach? A prospective study of 1000 patients. $N$ Engl J Med 1980; 303: 380-2.

11 Arwidsson S, Kock NG. Pathogenesis of multiple diverticula of the sigmoid colon in diverticular disease. Acta Chirurg Scand 1964: suppl 324.

12 Abrahamsson H, Lyrenas E, Dotevall G. Effects of beta - adrenoceptor blocking drugs on human sigmoid colonic motility. Dig Dis Sci 1983; 28: 590-94.

13 Ritchie J. Pain from distention of the pelvic colon by inflating a balloon in the irritable colon syndrome. Gut 1973; 14: 125-32.

14 Whitehead WE, Engel BT, Schuster MM. Irritable bowel syndrome. Physiological and psychological differences between diarrhoea-predominant and constipation predominant patients. Big Dis Sci 1980; 25: 404-13. 